\title{
Overview of medical malpractice in neurosurgery
}

\author{
*Collin J. Larkin, MSc, ${ }^{1}$ Anastasios G. Roumeliotis, BS, ${ }^{1}$ Constantine L. Karras, MD, ${ }^{1}$ \\ Nikhil K. Murthy, MD, ${ }^{1}$ Maria Fay Karras, JD, ${ }^{2}$ Huy Minh Tran, MD, ${ }^{3}$ Ketan Yerneni, BA, ${ }^{1}$ and \\ Matthew B. Potts, MD'
}

\begin{abstract}
1Department of Neurological Surgery and ${ }^{2}$ Pritzker School of Law, Northwestern University, Chicago, Illinois; and ${ }^{3}$ Department of Neurosurgery, Cho Ray Hospital, Ho Chi Minh City, Vietnam

Annually, $20 \%$ of all practicing neurosurgeons in the United States are faced with medical malpractice litigation. The average indemnity paid in a closed neurosurgical civil claim is $\$ 439,146$, the highest of all medical specialties. The majority of claims result from dissatisfaction following spinal surgery, although claims after cranial surgery tend to be costlier. On a societal scale, the increasing prevalence of medical malpractice claims is a catalyst for the practice of defensive medicine, resulting in record-level healthcare costs. Outside of the obvious financial strains, malpractice claims have also been linked to professional disenchantment and career changes for afflicted physicians. Unfortunately, neurosurgical residents receive minimal practical education regarding these matters and are often unprepared and vulnerable to these setbacks in the earlier stages of their careers. In this article, the authors aim to provide neurosurgical residents and junior attendings with an introductory guide to the fundamentals of medical malpractice lawsuits and the implications for neurosurgeons as an adjunct to more formal residency education.
\end{abstract}

https://thejns.org/doi/abs/10.3171/2020.8.FOCUS20588

KEYWORDS neurosurgery; medical malpractice; lawsuits

$\mathrm{N}$ EUROSURGICAL procedures are associated with the highest rate of medical malpractice claims. Approximately $20 \%$ of all neurosurgeons will be named as defendants in a malpractice claim on an annual basis, and nearly all neurosurgeons will be named defendants on a claim by the age of 65 years. ${ }^{1}$ Despite this, neurosurgical residents and junior attendings currently do not receive training in the legal intricacies associated with medical malpractice claims. Although this review does not replace the need for a standardized medicolegal curriculum and emphasis on such topics, our hope is that it can serve as a baseline for building the practical knowledge necessary for a successful career in neurosurgery.

Laws governing medical malpractice can vary substantially from state to state, and thus it is of paramount importance that every physician understand those governing in their state of practice. We will use the rules of the state of Illinois as an example throughout this paper.

\section{Medicolegal Basics}

What Is a Medical Malpractice Claim?

Medical malpractice claims fall under two categories of legal cases: civil (tort) claims and criminal charges. Crimi- nal charges against physicians are exceedingly rare, as they require egregious actions that violate the state's criminal code, resulting in the physician being arrested and charged by state prosecutors. The vast majority of medical malpractice claims result in civil litigation, which is a dispute between individuals and organizations. The patient typically brings a claim as the plaintiff against the defendant, usually a physician or medical group. Settlements between these parties may occur outside the judicial system at any phase of the lawsuit. Barring a settlement, the outcome of the case is determined in court by jurors and a judge; this court-approved resolution is required for class-action lawsuits. In malpractice claims, the plaintiff bears the burden of demonstrating that the defendant conducted negligent actions that resulted in patient suffering, thus deviating from acceptable standards of medical practice. This paper will focus on medical malpractice tort claims.

\section{What Constitutes Physician Negligence?}

Negligence is conduct, without wrongful intent, that falls below the minimum degree of ordinary care imposed by the law to protect others against unreasonable risk of harm. To prevail on a claim for medical malpractice, the 
plaintiff must establish by a preponderance of the evidence that the defendant acted negligently. The plaintiff must establish the four elements that constitute negligence: injury, duty, breach, and causation. The plaintiff must successfully demonstrate the presence of all four elements to substantiate the claim against the defendant. In most states, "it is the function of the jury, as trier of fact, to determine whether the plaintiff" has proven all the essential elements of a medical malpractice claim. ${ }^{2}$

\section{The Four Key Elements of Negligence: Injury, Duty, Breach, and Causation Injury}

The injury element is relatively straightforward: the plaintiff must establish that they have suffered a physical or emotional harm. The majority of medicolegal cases involve a physical injury.

\section{Duty}

Duty is the obligation to protect another against unreasonable risk of injury. A defendant is required to exercise the care that a reasonable person under the same circumstances would recognize as necessary to avoid or prevent an unreasonable risk of harm to another person. The standard of care is an objective measurement used in the medical field to determine reasonable prudence.

The Illinois Supreme Court has established that the standard of care requires "a physician to possess and apply that degree of knowledge, skill, and care which a reasonably well-qualified physician in the same or similar community would bring to a similar case under similar circumstances." 3 Accordingly, physicians are held to the same standard of care as other physicians within the same specialty. The plaintiff has the burden of establishing the applicable standard of care via expert testimony, often by a licensed physician in the same field. The expert must draw conclusions based on the recognized standards of competency within the specialty, rather than their own personal preferences. As stated, standard of care is measured by what a reasonably prudent person would do, rather than subjective preferences. Expert testimony may not be required in unique situations if the defendant's conduct is so grossly negligent that it is unnecessary or if the treatment is so common that any juror would be able to assess the liability of the defendant.

\section{Breach}

A breach of duty occurs when the defendant departs from the required standard of care and fails to act with reasonable prudence. This is the most difficult element for the plaintiff to establish in medical malpractice claims. Even with medical expert testimony, the standard of care for a given pathology is broad and accounts for the inherent risks of a procedure that a patient must knowingly consent to preoperatively. This element shields physicians because a defendant's actions must significantly deviate from the defined standard of care to establish breach of duty. A notable area in which physicians breach the duty of care is in failing to provide informed consent to their patients.
Neurological procedures and diseases bear significant risk of injury to the patient. However, if a plaintiff establishes an injury, the plaintiff must show that the physician deviated from the standard of care. In the field of neurological surgery, most complications arise from the heightened risk of injury, rather than the physician's failure to act within the acceptable standard of care. As long as the surgeon acted as a reasonably prudent surgeon would have acted under the circumstances, the plaintiff cannot prove breach, and their claim will be unsuccessful.

\section{Causation}

Lastly, the plaintiff must prove that the defendant's actions were both the actual cause and the legal cause of the plaintiff's injury. In essence, the plaintiff must prove that injury was both the direct result of the defendant's actions and was within the realm of reasonable possibility in the clinical scenario. Actual cause is established if the defendant's conduct physically caused the injury. A physician's actions are the actual cause if the injury would not have occurred without the physician's negligence. Legal cause is a legal limitation on actual cause, focusing on foreseeability. Most states require the plaintiff to have suffered a foreseeable harm that is not too remote or is within the risk created by the defendant's conduct. Legal cause requires that "the causal connection must not be contingent, speculative, or merely possible," but rather the injury sustained is a type that a reasonable person could foresee as a likely result of their conduct. ${ }^{4}$

Even if the plaintiff is unable to establish that the defendant was the actual cause of the injury, some states still allow plaintiffs to recover if the doctor's negligence diminished a patient's likelihood of achieving a favorable medical result. This is particularly relevant for neurosurgeons. In fact, the current Illinois precedence was established by a neurosurgical spine injury case. In Holton $v$ Memorial Hospital (679 NE2d 1202 [Ill Sup Ct 1997]), the plaintiff was diagnosed with thoracic discitis/osteomyelitis and was initially observed conservatively. The patient gradually became paraplegic and lost bowel and bladder function on the inpatient wards, but a lapse in communication between the nursing staff and the physician resulted in failure to properly diagnose and intervene in an appropriate time frame. The patient filed a medical malpractice claim and established injury through the loss-of-chance doctrine. Even though thoracic discitis was the actual cause of injury, the defendant's negligence (via inaction) diminished the patient's chance of a favorable medical result, and the plaintiff was able to recover damages. This doctrine and fear of repercussions from inaction-despite the clear indication for surgery in the above case study - may in fact sometimes lead to unnecessary interventions in indeterminate cases.

In summary, the plaintiff must prove by a preponderance of evidence all four elements of negligence (injury, duty, breach, and causation) to result in a successful medical malpractice claim. Of these, much time is spent analyzing duty, as a physician's exact responsibility to their patient in each unique setting can be nebulous. Once established, however, the plaintiff's onus of demonstrating breach tends to be a formidable challenge and barrier, as 
the standard of care is quite broad and accounts for most recognized, inherent risks. Despite this rigorous process, medical malpractice claims have become integral to the evolution of the medical landscape within the United States, and this is more apparent in neurosurgery than any other specialty.

\section{Practical Considerations for Neurosurgeons Medical Malpractice in the Context of Neurosurgery}

A study published in the New England Journal of Medicine surveyed more than 40,000 physicians and discovered that neurosurgeons experienced the highest annual rate of involvement in medical malpractice claims at $19.1 \%{ }^{1}$ Settlement or payout amounts in successful plaintiff verdicts regarding neurosurgical claims can be substantial, averaging $\$ 439,146 .{ }^{5}$ This medicolegal burden has altered clinical practices. For example, the sitting position for craniotomies has objective technical advantages in particular cases. However, its use has steadily declined due to its association with increased malpractice claims. ${ }^{6}$ In an effort to mitigate liability, neurosurgeons are increasingly resorting to the practice of "defensive medicine," which constitutes unnecessary and costly diagnostic workups and interventions. Defensive medicine does not shield one from liability, as physicians who are concerned about and mentally preoccupied by malpractice claims are just as likely to be sued as other colleagues.?

\section{Characteristics of Medical Malpractice in Neurological Surgery}

Multiple studies have aimed to elucidate risk factors for malpractice claims, including the type of surgery, physician and patient characteristics, and the element of care most targeted. A recent study published by Duke University in conjunction with the National Bureau of Economic Research examined 2131 closed medical malpractice claims filed against neurosurgeons obtained from Physician Insurers Association of America (PIAA), one of the largest medical professional liability data registries. ${ }^{5}$ Across all neurosurgical subspecialties, the chief factor (accounting for $42.1 \%$ of claims) contributing to medical malpractice was improper performance, defined as the neurosurgeon's performance during the perioperative period. The most prevalent condition resulting in malpractice claims is intervertebral disc pathology (20.6\%), primarily degeneration and displacement. Moreover, six of the seven most common pathologies resulting in malpractice claims were associated with the spinal column. From a procedural standpoint, spinal surgeries, including laminectomies, foraminotomies, discectomies, and fusions, were the most frequently associated with malpractice claims. While spinal pathologies and surgeries represent the majority of neurosurgical malpractice claims, the absolute number of spinal surgeries being performed in the United States far exceeds the number of cranial surgeries, at least partially accounting for this finding. ${ }^{5}$

The increased representation of spinal surgeries in neurosurgical malpractice claims is further evidenced in a study of 355 medical malpractice claims from The Doctors Company. ${ }^{11}$ Cases related to the spine represented
$52.1 \%$ of neurosurgical procedures resulting in malpractice claims. Additionally, the primary allegations by the plaintiff were associated with the perioperative period in $77.8 \%$ of claims, further corroborating the conclusions of the PIAA study. ${ }^{9}$ Despite lower absolute volume, cranial neurosurgeons are also vulnerable to malpractice litigation. According to the PIAA study, operative procedures involving the skull, brain, and cerebral meninges represented the fourth most frequent procedure resulting in a malpractice claim, at approximately $7.8 \%$ of claims. ${ }^{5}$

While spinal surgery malpractice claims typically arise from poor outcomes postoperatively and allege intraoperative negligence and poor performance, malpractice claims involving acute stroke management typically attempt to establish negligence by emphasizing a lack of timeliness in patient care, or failure to diagnose and treat. ${ }^{10}$ This demonstrates that it is imperative to not overlook the nonsurgical treatment and management of patients in the context of malpractice litigation. Routine monitoring of symptoms and disease progression is essential for optimal patient care and ensuring the physician's care falls within the standard of care. ${ }^{11}$

Patient characteristics and behaviors were one of the primary factors resulting in patient injury, regardless of the type of intervention, in $16.9 \%$ of medical malpractice claims from The Doctors Company analysis. ${ }^{11}$ Three comorbidities were noted to be of highest prevalence in patients who sustain injury: obesity (8\%), diabetes (5\%), and smoking (5\%). These comorbidities clearly alter a patient's risk profile; $18.6 \%$ of claims involved the assertion that the physician inadequately considered this risk profile, thus breaching the appropriate standard of care. Accordingly, a clear understanding of the comorbidities and their impact on surgical outcomes is crucial in optimizing outcomes and mitigating risk of malpractice claims. ${ }^{9}$ Careful patient selection for surgical intervention is critical. Many spine surgeries can be reframed in litigation to appear more elective in nature than originally understood, citing negligence in preoperative optimization. One study noted that patients with recent $(<6$ months) myocardial infarctions, coronary artery stents, and venous thromboembolic events were classified as "unsafe" patients and had an increased risk of poor surgical outcome. Such patients are not suitable for elective surgery until medically optimized and sufficient time for recovery has passed. Intervention despite an increased risk profile frequently provides the basis for a plaintiff's negligence claim. By performing a procedure on an inappropriate patient population, physicians are effectively breaching their duty by failing to adhere to the standard of care. ${ }^{12}$

\section{Motivations Underlying Medical Malpractice Claims}

Three distinct studies identified the following three primary motivations for filing medical malpractice claims: 1) holding the physician or health system accountable, 2) seeking an explanation for the adverse outcome, and 3) financial reward. While poor outcomes and financial incentives are certainly motivations in malpractice claims, the physician-patient relationship is the primary motivation. A good relationship can protect against claims while a poor relationship is a significant risk factor, independent 
of outcomes. The overwhelming majority of patients cited trust as the most important predictor for patient satisfaction, even greater than perceived clinical competence of the practitioner. ${ }^{8}$ Reasons cited for the breach in trust were a lack of empathy, poor listening skills, short office visits ( $<10$ minutes), insufficient explanations of medical conditions or treatment options, and the associated benefits and consequences of a given course of care..$^{13}$

Recent evidence from the Quality Outcomes Database further emphasized the importance of a strong physicianpatient relationship. A successful physician-patient relationship lies in communication. Distrust within the relationship is associated with poor outcomes. Patients seek alternative sources of care, resulting in disjointed patient management, and patients citing poor relationships with their physicians are less likely to abide by requested clinical guidelines, further jeopardizing outcomes. Moreover, patients with increased continuity of care were found to have a greater sense of trust in their physicians, and were less likely to file malpractice claims in the event of an adverse outcome. ${ }^{14} \mathrm{By}$ ensuring strong communication, the patient and the physician may confidently participate as partners in informed decision-making. With the physician as a partner, the patient will not view their provider as an adversary in the event of a poor outcome, thus reducing the risk of a malpractice claim. ${ }^{15}$

\section{Consequences of Medical Malpractice Litigation}

Neurosurgeons will greatly benefit from having an understanding of the financial and professional implications of a medical malpractice claim. Financially, the average indemnity paid in a closed claim in neurosurgery between 2003 and 2012 was $\$ 439,146$, according to the PIAA. ${ }^{5}$ This is $35 \%$ greater than the average indemnity paid among all medical specialties, further emphasizing the impact of litigation on the practice of neurosurgery. ${ }^{5}$ The average payment varies with the type of malpractice claim and associated pathology. While the absolute number of claims involving spinal surgeries far exceeds those involving cranial surgeries or errors in medical management, their claims tend to be less costly. The average indemnities paid for errors in medical management and negligence in cranial procedures were $\$ 423,539$ and $\$ 438,183$, respectively, as opposed to the average indemnity payment of $\$ 278,362$ in claims associated with spinal procedures. ${ }^{11}$ While the majority of these costs are covered by malpractice insurance, physicians pay high annual premiums that frequently exceed $\$ 100,000$, depending on the extent of coverage and state of practice.

The financial costs imposed on physicians are in addition to the professional costs a physician may face following a malpractice claim. While rare, medical malpractice allows the state to withdraw licensure and bar future practice. This can be both financially and emotionally devastating for neurosurgeons who have spent enormous amounts of time and effort training to serve others. Technology allows for news of malpractice claims to rapidly spread and tarnish future encounters and relationships with patients. According to a qualitative study of 23 neurosurgeons, one of the worst outcomes of malpractice litigation was professional disenchantment. ${ }^{16}$ Following litigation, physicians are at risk of losing the passion that fueled their journeys and the satisfaction they gained from operating and serving patients. As a result, several surgeons even elected to change careers and pursue consulting or medical startup companies. Finally, the added negative pressure to perform (that may result from prior malpractice litigation) has an impact on personal lives, potentially exposing an uncharted dark side of the field. ${ }^{16}$

\section{Defensive Medicine}

In response to the lurking threats of medical malpractice claims and associated financial and professional implications, neurosurgeons have resorted to practicing defensive medicine. Defensive medicine may include ordering extraneous laboratory tests, imaging, medications, and referrals, or even altering indications and thresholds for performing certain surgeries. The growing practice of defensive medicine is one factor, albeit among many others, that has contributed to the rising cost of healthcare in the United States, now accounting for a staggering almost $20 \%$ of the US annual gross domestic product. ${ }^{17}$ Increased costs introduce further barriers for patients to access necessary healthcare resources, creating a paradoxical cycle that ultimately diminishes overall quality of care.

Recently, an online survey of 1026 members of the American Board of Neurological Surgery noted that spine surgeons practice defensive medicine at a significantly higher rate than nonspine neurosurgeons $(89.2 \%$ vs $84.6 \%$, $\mathrm{p}=0.031$ ). Multivariate analysis concluded that neurological spine surgeons were three times more likely to practice defensive medicine than nonspine neurosurgeons when controlling for high-risk procedures, malpractice premiums, and percentage of patients on governmental insurance. These stark differences are present despite the similar annual malpractice premiums paid among spine and nonspine neurosurgeons $(\$ 104,480.52$ vs $\$ 101,721.76$, $\mathrm{p}=0.60) .{ }^{18}$ These results are partially explained by our previously noted findings that patients undergoing spine surgery seem to be more litigious on average than their counterparts undergoing cranial surgery.

\section{Conclusions}

Medical malpractice has marked its growing presence in today's neurosurgical landscape, with nearly $20 \%$ of practicing neurosurgeons facing a malpractice lawsuit in the next year alone. ${ }^{1}$ A successful malpractice claim requires the plaintiff to establish that the defendant doctor acted negligently by deviating from the standard of care. The four pillars of negligence that must be shown include injury, duty, breach, and causation (Fig. 1). The majority of claims fail in their attempt to establish breach, as the standard of care is loosely defined, and most consented risks are not viewed as a deviation from standard care. Positive physician-patient relationships result in better outcomes and tend to be protective against malpractice claims, and communication and trust are the foundations of a good relationship. On a positive note, medical malpractice helps ensure that physicians are held accountable for their substantial levels of responsibility to patients. We should aim to continuously educate ourselves as a profes- 


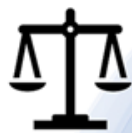

4 Elements of Negligence:

1) Injury

2) Duty

3) Breach

4) Causation

Most common underlying cause:

poor physician-patient relationship

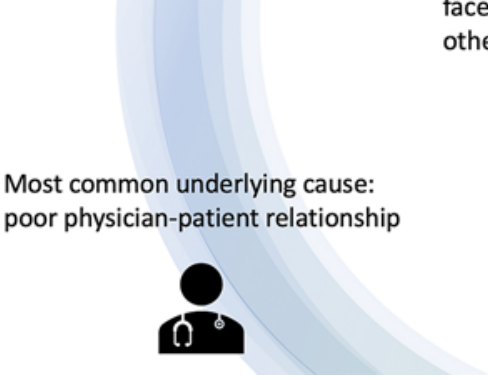

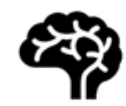

Neurosurgeons are more likely to face a malpractice claim than any other physician (19.1\% annually)

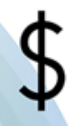

Average indemnity paid in neurosurgical malpractice suits: $\$ 439 \mathrm{k}$

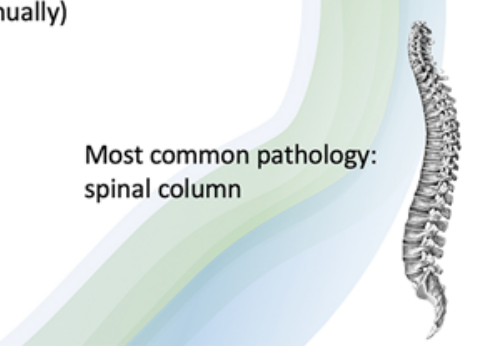

FIG. 1. Summary graphic of medical malpractice in the context of neurosurgery.

sion regarding medicolegal matters to protect ourselves both financially and professionally, and to ensure that we are providing the safest and best care possible to our patients.

\section{References}

1. Jena AB, Seabury S, Lakdawalla D, Chandra A. Malpractice risk according to physician specialty. N Engl J Med. 2011; 365(7):629-636.

2. Steele v Provena Hospitals, 111 Ill2d 229 (Ill App Ct 2013).

3. Purtill v Hess, 996 NE2d 711 (Ill App Ct 1986).

4. Illinois Jurisprudence: Health Care Law. Vol 27. LexisNexis; 2018.

5. Elsamadicy AA, Sergesketter AR, Frakes MD, Lad SP. Review of neurosurgery medical professional liability claims in the United States. Neurosurgery. 2018;83(5):997-1006.

6. Porter JM, Pidgeon C, Cunningham AJ. The sitting position in neurosurgery: a critical appraisal. Br J Anaesth. 1999; 82(1):117-128.

7. Juo Y-Y, Lewis C, Hanna C, et al. An innovative approach for familiarizing surgeons with malpractice litigation. J Surg Educ. 2019;76(1):127-133.

8. Schleiter KE. Difficult patient-physician relationships and the risk of medical malpractice litigation. Virtual Mentor. 2009; 11(3):242-246.

9. Taylor CL. Neurosurgical practice liability: relative risk by procedure type. Neurosurgery. 2014;75(6):609-613.

10. Haslett JJ, Genadry L, Zhang X, et al. Systematic review of malpractice litigation in the diagnosis and treatment of acute stroke. Stroke. 2019;50(10):2858-2864.

11. Taylor CL, Ranum D. Patient safety in neurosurgical practice: physician and patient factors that contribute to patient injury. World Neurosurg. 2016;93:159-163.

12. Epstein NE. What can spine surgeons do to improve patient care and avoid medical negligence suits? Surg Neurol Int. 2020;11:38.

13. Roter D. The patient-physician relationship and its implications for malpractice litigation. J Health Care Law Policy. 2006;9:304-314.
14. Asher AL, Knightly J, Mummaneni PV, et al. Quality Outcomes Database Spine Care Project 2012-2020: milestones achieved in a collaborative North American outcomes registry to advance value-based spine care and evolution to the American Spine Registry. Neurosurg Focus. 2020;48(5):E2.

15. Hickson GB, Jenkins AD. Identifying and addressing communication failures as a means of reducing unnecessary malpractice claims. NC Med J. 2007;68(5):362-364.

16. Guillain A, Moncany AH, Hamel O, et al. Spine neurosurgeons facing the judicialization of their profession: disenchantment and alteration of daily practice - a qualitative study. Acta Neurochir (Wien). 2020;162(6):1379-1387.

17. McCarthy M. US healthcare spending will reach $20 \%$ of GDP by 2024, says report. BMJ. 2015;351:h4204.

18. Din RS, Yan SC, Cote DJ, et al. Defensive medicine in U.S. spine neurosurgery. Spine (Phila Pa 1976). 2017;42(3):177185 .

\section{Disclosures}

The authors report no conflict of interest concerning the materials or methods used in this study or the findings specified in this paper.

\section{Author Contributions}

Conception and design: CL Karras, Larkin, Roumeliotis, Potts. Acquisition of data: CL Karras, Larkin, Roumeliotis. Analysis and interpretation of data: Larkin, Roumeliotis. Drafting the article: Larkin, Roumeliotis. Critically revising the article: all authors. Reviewed submitted version of manuscript: all authors. Approved the final version of the manuscript on behalf of all authors: CL Karras. Administrative/technical/material support: Larkin, Roumeliotis.

\section{Correspondence}

Constantine L. Karras: Northwestern University, Feinberg School of Medicine, Chicago, IL. constantine.karras@northwestern.edu. 